\title{
Effect of the number, position and length of alkyl chains on the physical and thermal properties of poly- substituted pyridinium ionic liquids
}

\author{
Pedro Verdía, ${ }^{a}$ Marta Hernaiz, ${ }^{b}$ Emilio J. González, ${ }^{c}$ Eugénia A. Macedo, ${ }^{c}$ Josefa \\ Salgado ${ }^{d}$ and Emilia Tojo ${ }^{a^{*}}$ \\ ${ }^{a}$ Organic Chemistry Department, Faculty of Chemistry, University of Vigo, 36310 Vigo, \\ Spain; ${ }^{b}$ Tekniker, Otaola 20, P.K.44, 20600 Eibar, Gipuzkoa, Spain; ${ }^{c}$ LSRE-Laboratory \\ of Separation and Reaction Engineering, University of Porto, Porto 4200-465, \\ Portugal; ' ${ }^{d}$ Applied Physic Department, Faculty of Physics, University of Santiago de \\ Compostela, 15782 Santiago de Compostela, Spain
}

\begin{abstract}
Five ionic liquids derived from pyridinium cation polysubstituted with different alkyl chains were synthesized. Their thermal properties (phase transition and decomposition temperatures) and physical properties (density, speed of sound, refractive index and viscosities) were evaluated. The effect of the number of alkyl chains, their length and their position on the pyridinium ring over the studied physical and thermal properties is also analyzed and discussed.
\end{abstract}

\section{Keywords}

Ionic liquids; Pyridinium; Decomposition temperature; Density; Speed of sound; Refractive index; Viscosity

\section{Introduction}

One of the most promising industrial applications of ILs is their use in the extractive desulfurization of fuels, which has been recently reviewed [1]. Studies of Holbrey and co-workers [2] have shown that the extractive ability of ILs is mainly affected by the cation type, and vary following the sequence dimethylpyridinium > methylpyridinium > pyridinium $\approx$ imidazolium $\approx$ pyrrolidinium. More recently, it has been shown that the tetraalkylsubstituted pyridinium ILs 1-ethyl-3,5-dimethyl-2-pentylpyridinium bis(trifluoromethanesulfonyl)imide $\left[{ }^{1} \mathrm{E}^{3} \mathrm{M}^{5} \mathrm{M}^{2} \mathrm{PPy}\right]\left[\mathrm{NTf}_{2}\right]$ and 1-butyl-3,5-dimethyl-2pentylpyridinium bis(trifluoromethanesulfonyl)imide $\left[{ }^{1} \mathrm{~B}^{3} \mathrm{M}^{5} \mathrm{M}^{2} \mathrm{PPy}\right]\left[\mathrm{NTf}_{2}\right]$ present 
high values of selectivity and solute distribution ratio when used as solvent for extraction of thiophene from heptane [3].

The knowledge of the physical properties of an IL is very important to evaluate its capacity for a particular application. Taking into account the interest of polysubstituted pyridinium based ILs as extractants for fuels, thermal decomposition temperature, density, speed of sound, refractive index, and viscosities of a series of five ILs derived from pyridinium cation substituted with different alkyl chains are reported in this work. The influence of the number of cation alkyl chains, their length, and their position on the pyridinium ring, on the ionic liquid physical properties is also analysed and discussed.

\section{Experimental}

The ILs were synthesized from 2,3,5-trimethylpyridine according to a procedure previously reported [3]. Their structures are shown in Scheme 1. Their structures were determined by ${ }^{1} \mathrm{H},{ }^{13} \mathrm{C}$ and ${ }^{19} \mathrm{~F}$ NMR spectroscopy and confirmed by comparison with previously described data [3]. All ILs were dried by heating at (373.15 to $383.15 \mathrm{~K}$ ) and stirring under high vacuum $\left(2 \times 10^{-1} \mathrm{~Pa}\right)$ for $48 \mathrm{~h}$ before use. Their purity was estimated by ${ }^{1} \mathrm{H}$ NMR (400 MHz) showing to be no less than $99 \%$.

$$
\begin{aligned}
& \text { 2.RX } M e \\
& 1, R_{1}=E t, R_{2}=P e \\
& 2, R_{1}=B u, R_{2}=P e \\
& 3, R_{1}=\mathrm{He}, R_{2}=M e \\
& 4, R_{1}=\mathrm{He}, R_{2}=E t \\
& 5, R_{1}=\mathrm{He}, R_{2}=P e
\end{aligned}
$$

Scheme 1. Synthetic procedure and structures of the polyalkylpyridinium ILs studied in this work.

\section{Results and Discussion}

The analysis by DSC of the studied ILs shows that they are liquids at room temperature and no melting temperature $\left(T_{\mathrm{m}}\right)$, cold crystallization temperature $\left(T_{\mathrm{cc}}\right)$ or glass transition temperature $\left(T_{\mathrm{g}}\right)$ were detected at the studied temperature range. The thermal stability of the ILs investigated linked to decomposition temperatures are listed in Table 2. These values were calculated by TGA and DSC (complementary techniques) under $\mathrm{N}_{2}$ atmosphere. As compiled in Table 2, both techniques provide similar results and the same behavior was observed. As it can be observed, a change in the length of the cation alkyl substituents shows a very small effect on $T_{\text {decom, }}$ either if the alkyl group is located 
on position 1 (e.g., $\left[{ }^{1} \mathrm{E}^{3} \mathrm{M}^{5} \mathrm{M}^{2} \mathrm{PPy}\right]\left[\mathrm{NTf}_{2}\right]$ (1) vs. $\left[{ }^{1} \mathrm{~B}^{3} \mathrm{M}^{5} \mathrm{M}^{2} \mathrm{PPy}\right]\left[\mathrm{NTf}_{2}\right]$ (2) vs. $\left.\left[{ }^{1} \mathrm{H}^{3} \mathrm{M}^{5} \mathrm{M}^{2} \mathrm{PPy}\right]\left[\mathrm{NTf}_{2}\right](\mathbf{5})\right)$, or if it is located on position $2\left(\left[{ }^{1} \mathrm{H}^{2} \mathrm{M}^{3} \mathrm{M}^{5} \mathrm{MPy}\right]\left[\mathrm{NTf}_{2}\right](\mathbf{3})\right.$ vs. $\left[{ }^{2} \mathrm{E}^{1} \mathrm{H}^{3} \mathrm{M}^{5} \mathrm{MPy}\right]\left[\mathrm{NTf}_{2}\right]$ (4) vs. $\left[{ }^{1} \mathrm{H}^{3} \mathrm{M}^{5} \mathrm{M}^{2} \mathrm{PPy}\right]\left[\mathrm{NTf}_{2}\right]$ (5)). The same behaviour has been already observed for other related ILs [4,5].

Table 2. Thermal decomposition temperatures, $T_{\text {decom }}$, calculated by TGA and DSC for the studied ILs.

\begin{tabular}{llcc}
\hline IL & Abbreviation & $\boldsymbol{T}_{\text {decom }}$ TGA / (K) & $\boldsymbol{T}_{\text {decom }}$ DSC / (K) \\
$\mathbf{1}$ & {$\left[{ }^{1} \mathrm{E}^{3} \mathrm{M}^{5} \mathrm{M}^{2} \mathrm{PPy}\right]\left[\mathrm{NTf}_{2}\right]$} & 641 & 640 \\
$\mathbf{2}$ & {$\left[{ }^{1} \mathrm{~B}^{3} \mathrm{M}^{5} \mathrm{M}^{2} \mathrm{PPy}\right]\left[\mathrm{NTf}_{2}\right]$} & 638 & 648 \\
$\mathbf{3}$ & {$\left[{ }^{1} \mathrm{H}^{2} \mathrm{M}^{3} \mathrm{M}^{5} \mathrm{MPy}\right]\left[\mathrm{NTf}_{2}\right]$} & 643 & 663 \\
$\mathbf{4}$ & {$\left[{ }^{2} \mathrm{E}^{1} \mathrm{H}^{3} \mathrm{M}^{5} \mathrm{MPy}\right]\left[\mathrm{NTf}_{2}\right]$} & 630 & 639 \\
$\mathbf{5}$ & {$\left[{ }^{1} \mathrm{H}^{3} \mathrm{M}^{5} \mathrm{M}^{2} \mathrm{PPy}\right]\left[\mathrm{NTf}_{2}\right]$} & 637 & 625 \\
\hline
\end{tabular}

\subsection{Physical Properties}

Experimental data of density, $\rho$, speed of sound, $u$, refractive index, $n_{\mathrm{D}}$ and kinematic viscosity, $v$, of the pure ionic liquid were determined from $T=(298.15$ to 343.15$) \mathrm{K}$ and atmospheric pressure. Their experimental data and temperature dependence is plotted in Figure 3.
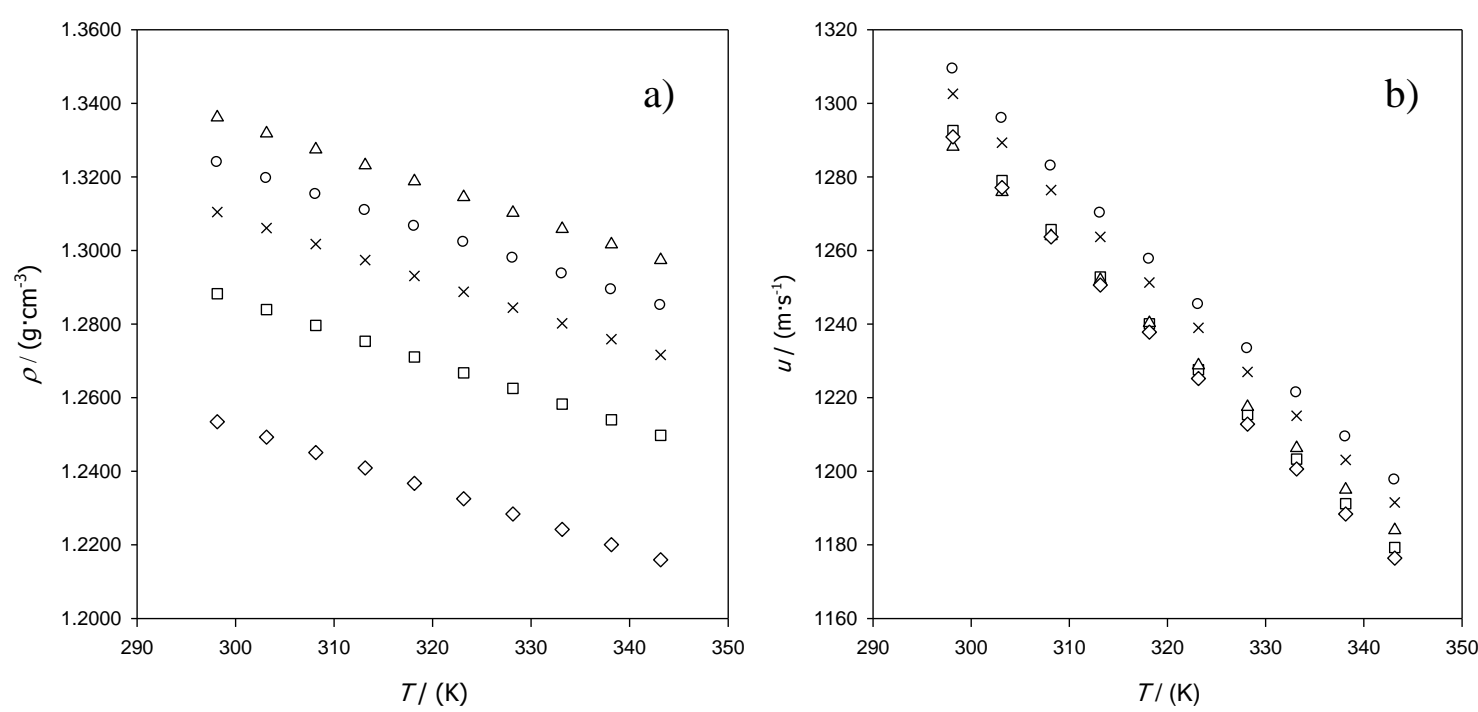

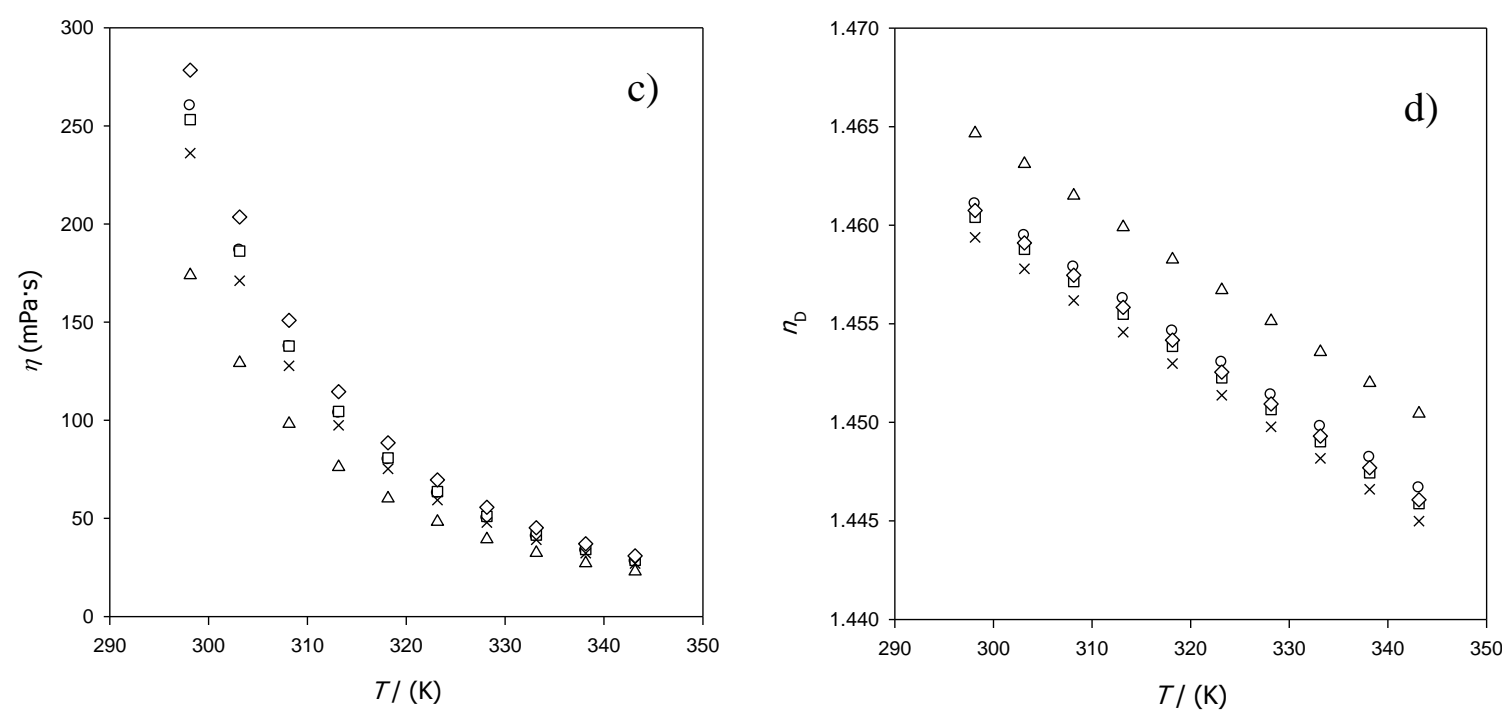

Figure 3. Temperature dependence of the physical properties of the studied ILs: a) density; b) speed of sound; c) dynamic viscosity; and d) refractive index. Symbols: (o) [ $\left.{ }^{1} \mathrm{E}^{3} \mathrm{M}^{5} \mathrm{M}^{2} \mathrm{PPy}\right]\left[\mathrm{Nf}_{2}\right]$ (1) ; (口) $\left[{ }^{1} \mathrm{~B}^{3} \mathrm{M}^{5} \mathrm{M}^{2} \mathrm{PPy}\right]\left[\mathrm{NTf}_{2}\right](\mathbf{2}) ;(\triangle)\left[{ }^{1} \mathrm{H}^{2} \mathrm{M}^{3} \mathrm{M}^{5} \mathrm{MPy}\right]\left[\mathrm{NTf}_{2}\right]$ (3); (×) $\left[{ }^{2} \mathrm{E}^{1} \mathrm{H}^{3} \mathrm{M}^{5} \mathrm{MPy}\right]\left[\mathrm{NTf}_{2}\right]$ (4), and $(\diamond)\left[{ }^{1} \mathrm{H}^{3} \mathrm{M}^{5} \mathrm{M}^{2} \mathrm{PPy}\right]\left[\mathrm{NTf}_{2}\right](\mathbf{5})$.

\section{Conclusions}

In the evaluated temperature range (cooling from $393 \mathrm{~K}$ to $243 \mathrm{~K}$ ), all the investigated compounds are liquids and no melting point, glass transition temperature, or cold crystallization temperature were detected. However, a change in the length of the cation alkyl substituents shows a very small effect on decomposition temperature.

Density, speed of sound and refractive index show a linear dependence with temperature while viscosity decreases exponentially with it. As the alkyl chain length increases, density decreases and viscosity increases; either if the alkyl group is located on position 1 or it is located on position 2. The same trend was also obtained for the speed of sound when the alkyl chain on position 1 is elongated. The experimental refractive indices are quite similar for all the studied ionic liquid, suggesting that, in this case, the refractive index is not very affected by the alkyl chain length.

Density decrease is observed when a new alkyl chain is added to the ring, while the other physical properties (speed of sound, refractive index and viscosity) increase.

The main conclusion of this work is that the studied physical properties of this type of ILs mainly depend on the number and length of the alkyl substituents, while the effect of the alkyl chain position is less important. This is a very interesting result taking into 
account that the synthetic procedure needed to introduce an alkyl substituent longer than a methyl group on position 2 is much more expensive and time-consuming than that needed to introduce an alkyl group on position 1 .

\section{Acknowledgments}

The authors are grateful to the Ministerio de Economía y Competitividad of Spain (Ref. DPI2012-38841-C02-02), to the Xunta de Galicia (projects PGIDIT04BTF301031PR and CN 2012/184) and the Galician Network on Ionic Liquids, 408 REGALIs (CN 2012/120), for financial support. This work was partially supported by project PEstC/EQB/LA0020/2011, financed by FEDER through COMPETE - Programa Operacional Factores de Competitividade and Fundação para a Ciência e a Tecnologia FCT (Portugal). E.J.G. is thankful to FCT for his postdoctoral grant (SFRH/BPD/70776/2010).

\section{References}

[1] E. Kowsari, Recent Advances in the Science and Technology of Desulfurization of Diesel Fuel Using Ionic Liquids, InTech, 2013, http://dx.doi.org/10.5772/51651.

[2] J.D. Holbrey, I. López-Martín, G. Rothenberg, K.R. Seddon, G. Silvero, X. Zheng, Green Chem. 10 (2008) 87-92.

[3] P. Verdía, E.J. González, B. Rodríguez-Cabo, E. Tojo, Green Chem. 113 (2011) 2768-2776.

[4] J.M. Crosthwaite, M.J. Muldoon, J.K. Dixon, J.L. Anderson, J.F. Brennecke, J. Chem. Thermodynamics 37 (2005) 559-568.

[5] J.G. Huddleston, A.E. Visser, W.M. Reichert, H.D. Willauer, G.A. Broker, R.D. Rogers, Green Chem. 3 (2001) 156-164. 